REAL, G.S.C.P.C. et al. Comercialização do pescado no Município de Campos dos Goytacazes RJ. PUBVET, Londrina, V. 5, N. 28, Ed. 175, Art. 1184, 2011.

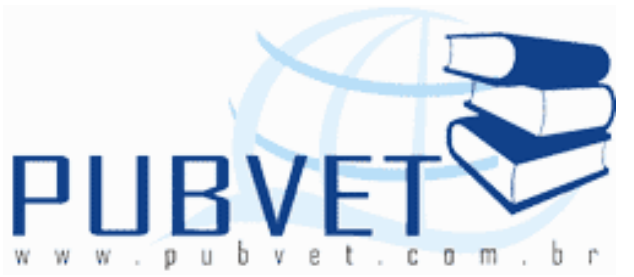

PUBVET, Publicações em Medicina Veterinária e Zootecnia.

\title{
Comercialização do pescado no Município de Campos dos Goytacazes -
} RJ

Gabriela Soares Carvalho Pamplona Corte Real ${ }^{1}$; Marize Bastos de Matos ${ }^{1}$; Michelle Sant'Anna Lyra², Dálcio Ricardo de Andrade ${ }^{3}$

${ }^{1}$ Doutorandas do Programa de Pós-Graduação em Ciência Animal - UENF/LZNA. e-mail: gabrielapamplona@yahoo.com.br; marizezootecnia@yahoo.com.br 2Zootecnista; Mestre em Ciência Animal do Programa de Pós Graduação em Ciência Animal - UENF/CCTA/LZNA.

${ }^{3}$ Professor titular do Programa de Pós Graduação em Ciência Animal UENF/CCTA/ LZNA. e-mail: dalcio@uenf.br

\section{Resumo}

Uma pesquisa foi desenvolvida no Município de Campos dos Goytacazes ao longo de três anos, com o objetivo de se obter um panorama da piscicultura local. Nesta abordagem, foram aplicados questionários aos comerciantes e pescadores, cujas principais perguntas foram relacionadas às espécies vendidas, preço, métodos de conservação, peixes mais vendidos e mais procurados, expectativas de melhora em relação à comercialização e exploração. Não foram verificadas variações ao longo dos três anos para a venda de peixes, esta estabilidade dos preços, ocorreu principalmente pela baixa inflação no período avaliado. Não ocorreu variação dos locais de extração dos peixes comercializados, visto que todos são pertencentes a lagoas, rios e 
REAL, G.S.C.P.C. et al. Comercialização do pescado no Município de Campos dos Goytacazes RJ. PUBVET, Londrina, V. 5, N. 28, Ed. 175, Art. 1184, 2011.

mares próximos. A comercialização de espécies marinhas e de água doce no município de Campos está se desenvolvendo lentamente. Os comerciantes e pescadores têm expectativas de melhoras desde que se tenha maior investimento em infraestrutura por parte do poder público.

Palavras-chave: comércio; conservação; peixes

\section{Commercialization of the fish in Campos dos Goytacazes city - RJ}

\section{Abstract}

Over three years, a survey was conducted in Campos dos Goytacazes city, in order to obtain an overview of pisciculture local. In this approach, questionnaires were applied to traders and fishermen, whose the main questions were related to the species sold, prices and conservation methods, fish-selling and most wanted, expectations of improvement in the marketing and exploration. No changes were observed over the three years for the sale of fish, that price stability was mainly due to low inflation in the period evaluated. There was no variation in the local extraction of marketable fish, seeing that all are owned by ponds, rivers and seas nearby. The marketing of marine species and freshwater in Campos city is developing slowly. Traders and fishermen have expectations of improvements since it has increased investment in infrastructure by the government.

Keywords: trader; conservation; fish

\section{Introdução}

A piscicultura é uma exploração animal que vem se tornando importante ao longo dos anos, como fonte de proteína para o consumo humano, com um produto de alta qualidade nutricional.

Durante décadas, a produção pesqueira no Brasil não recebeu a devida atenção governamental, o que refletiu na produção, que permaneceu estagnada por um bom período. Com a adoção de uma série de medidas, o 
REAL, G.S.C.P.C. et al. Comercialização do pescado no Município de Campos dos Goytacazes RJ. PUBVET, Londrina, V. 5, N. 28, Ed. 175, Art. 1184, 2011.

setor passou a responder a esses estímulos através da consolidação das políticas públicas.

Dados do ano de 2009 mostram que a produção brasileira de pescado aumentou $25 \%$ nos últimos 8 anos anteriores, passando de 991 mil toneladas anuais para 1,24 milhões de toneladas. Somente a piscicultura teve uma elevação de $60,2 \%$ em 2008 e 2009, na comparação com 2007. A criação de tilápia chegou a 132 mil toneladas/ano sendo o principal produto aquícola e representou $39 \%$ do total de pescado cultivado. Outra espécie que também apresentou um crescimento significativo de produção foi o tambaqui, que passou de 30,6 mil toneladas para 46,4 mil toneladas/ano (MPA, 2010).

O Nordeste, de acordo com dados de 2009, é a maior região produtora de pescado do Brasil com 411 mil toneladas/ano, seguida da região Sul, com 316 mil/ano, região Norte, com 263 mil toneladas, a Sudeste, com 177 mil e, por último, Centro-oeste, com 72 mil. Santa Catarina é o maior produtor entre os estados, com 207 mil toneladas/ano, seguida do Pará, com 136 mil toneladas. A Bahia, com 119 mil toneladas, é o terceiro maior produtor nacional seguida de perto pelo Ceará, com 88 mil toneladas (MPA, 2010).

Até o final de 2011, a expectativa do Ministério da Pesca e Aquicultura MPA é de que a produção total de pescado atinja a meta de 1,43 milhão de toneladas, conforme previsto no plano "Mais Pesca e Aquicultura", lançado pelo governo em 2008. De acordo com essas projeções, a aquicultura responderá por cerca de 570 mil toneladas/ano e a pesca extrativa, tanto marítima quanto continental, com cerca de 860 mil toneladas/ano (MPA, 2010).

De acordo com a FIPERJ (Fundação Instituto de Pesca do Estado do Rio de Janeiro), no ano de 2002, o estado do Rio de Janeiro, ocupava o sexto lugar em capturas brasileiras, atrás do Pará, Santa Catarina, Bahia, Rio Grande do Sul e Amazonas. Com litoral de aproximadamente $635 \mathrm{~km}$ de extensão e uma frota estimada em 2731 embarcações (FIPERJ, 2002).

Em relação à região do Norte Fluminense onde se situa o município de Campos dos Goytacazes, o levantamento de dados é escasso, mas dados de 
REAL, G.S.C.P.C. et al. Comercialização do pescado no Município de Campos dos Goytacazes RJ. PUBVET, Londrina, V. 5, N. 28, Ed. 175, Art. 1184, 2011.

1997 mostram que a pesca da região correspondeu a 14\% do desembarque do estado do Rio de Janeiro (FIPERJ, 1997).

O objetivo deste estudo foi avaliar, ao longo de três anos, o panorama da comercialização de pescado no município de Campos dos Goytacazes - RJ.

\section{Material e Métodos}

Uma pesquisa foi realizada no Mercado Municipal de Campos dos Goytacazes - RJ conforme localização na Figura 1.

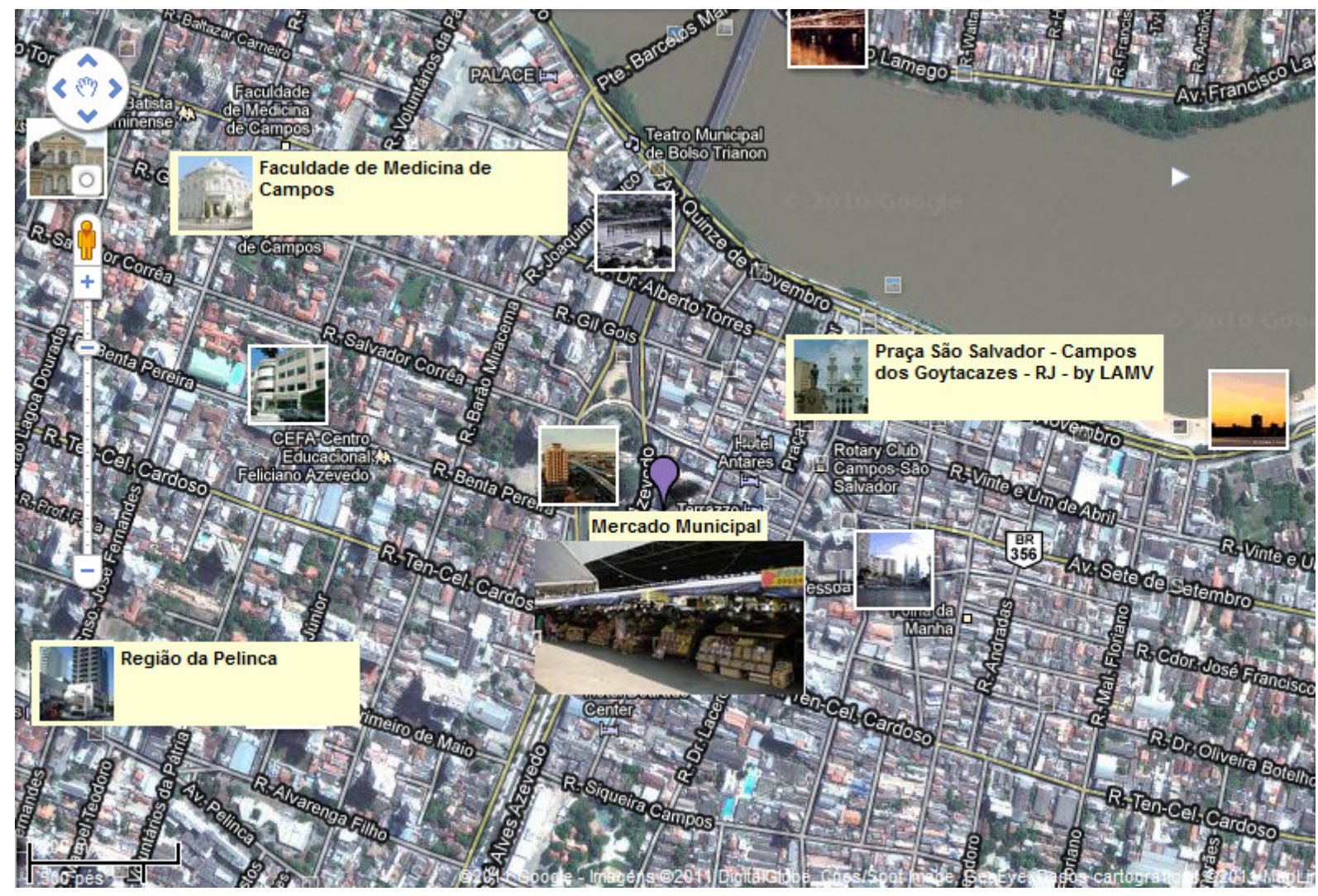

Figura 1: Localização geográfica do Mercado Municipal de Campos dos Goytacazes, RJ.

Fonte: googlemaps, 2011.

O mercado fica localizado no centro da cidade e próximo a bairros importantes, sendo um ponto estratégico no cenário municipal. Este possui 87 anos de existência, com venda de diversos produtos agropecuários. Nele situase o mercado de peixe do município, com 46 bancas no total, todas revestidas 
REAL, G.S.C.P.C. et al. Comercialização do pescado no Município de Campos dos Goytacazes RJ. PUBVET, Londrina, V. 5, N. 28, Ed. 175, Art. 1184, 2011.

de azulejos e nestas bancas, vendem-se peixes marinhos e de água doce, assim como camarões e siris.

Os mercadores foram questionados, nos anos de 2008, 2009 e 2010, com o intuito de verificar-se a situação da piscicultura no município, tendo como principais perguntas: as espécies comercializadas e seus respectivos preços; origem das espécies; método de conservação e transporte; como os peixes são trazidos (sujos, limpos, etc.); forma de comercialização dos peixes (inteiro, posta, filé, etc.); se são vendidos ovas de peixe; peixes que já foram comercializados e atualmente estão com dificuldades de encontrar; de onde vinham os peixes que não são mais encontrados; o peixe mais vendido e o mais procurado e as principais dificuldades encontradas na comercialização.

\section{Resultados e Discussão}

A partir do questionário de cada banca ao longo dos anos e a média de respostas das questões levantadas foi possível verificar que não houve variação ao longo dos três anos, em relação às espécies e seus preços conforme Tabela 1, uma vez que mesmo sem avaliação estatística foi possível identificar uma repetibilidade das respostas. Uma razão para possível permanência de todas as variedades de peixes encontradas é a conscientização da época de defeso.

A quantidade de peixes comercializados são em média de 80-150 $\mathrm{kg} / \mathrm{box} / \mathrm{semana}$ e a facilidade de captura contribuiu para a quantidade de peixes ofertada, uma vez que muitos dos comerciantes são os próprios pescadores e moram próximos aos locais de pesca.

A estabilidade dos preços do pescado ao longo dos anos ocorreu principalmente pelo controle da inflação dentro dos parâmetros estabelecidos pela economia brasileira no período avaliado. A inflação de 2008 (5,9\%) ficou dentro dos parâmetros estabelecidos pelo Banco Central. No ano de 2009 $4,3 \%$, a menor inflação desde 2006.e para o ano de $2010-5,9 \%$, semelhante a $2008(B C B, 2011)$ 
REAL, G.S.C.P.C. et al. Comercialização do pescado no Município de Campos dos Goytacazes RJ. PUBVeT, Londrina, V. 5, N. 28, Ed. 175, Art. 1184, 2011.

Tabela 1- Média de preços e comercialização por espécies ao longo de três anos consecutivos no mercado de peixes do município de Campos dos Goytacazes - RJ.

\begin{tabular}{|c|c|c|c|}
\hline \multicolumn{4}{|c|}{$2008-2009-2010$} \\
\hline & Preço & Peixes Água & Preço \\
\hline Peixes Marinhos & $\mathrm{R} \$$ & Doce & $\mathrm{R} \$$ \\
\hline Anchova & $8,00-10,00$ & Acará & $2,00-4,00$ \\
\hline Peroá & $8,00-14,00$ & Bagre & $3,00-5,00$ \\
\hline Cação & $10,00-15,00$ & Bagre Africano & $3,00-5,00$ \\
\hline Curvina & $5,00-10,00$ & Cascudo & $2,00-3,00$ \\
\hline Dourado & $7,00-10,00$ & Curimatã & $3,00-6,00$ \\
\hline Espada & 3,00 & Jundiá & $3,00-6,50$ \\
\hline Galo & 3,50 & Manjuba & 5,00 \\
\hline Namorado & $6,00-9,00$ & Moroba & 4,00 \\
\hline Pargo & $4,00-8,00$ & Piabanha & $4,00-6,00$ \\
\hline Pejereba & 10,00 & Piau & $5,00-8,00$ \\
\hline Peroá & $8,00-14,00$ & Piaba & 2,00 \\
\hline Pescada & $6,00-15,00$ & Robalo & $10,00-18,00$ \\
\hline Sarda & $7,00-8,00$ & Saíru & $1,00-2,50$ \\
\hline Tainha & $4,00-8,00$ & Tainha & $3,00-8,00$ \\
\hline \multirow[t]{3}{*}{ Xareu } & $5,00-6,00$ & Tambaqui & $3,00-4,00$ \\
\hline & & Tilápia & $3,00-6,00$ \\
\hline & & Traíra & $3,00-8,00$ \\
\hline
\end{tabular}

Todos os peixes comercializados são retirados das lagoas (Lagoa do Campelo, Lagoa Feia, Lagoa de Cima, Ponta Grossa, Fidalgo e Barra do Furado), rio (Paraíba do Sul) e mares próximos (Farol de São Tomé, Macaé, Atafona e Mondel) de maneira extrativista.

O principal método de conservação encontrado foi o isopor com gelo. Geralmente, os peixes marinhos são entregues em caminhões com gelo, sendo 
REAL, G.S.C.P.C. et al. Comercialização do pescado no Município de Campos dos Goytacazes RJ. PUBVET, Londrina, V. 5, N. 28, Ed. 175, Art. 1184, 2011.

vendidos em caixas com $20 \mathrm{~kg}$ e sujos. Já os peixes de água doce são transportados pelos comerciantes em carros particulares.

Os próprios comerciantes das bancas que limpam os peixes (evisceração) e de acordo com o pedido dos consumidores fazem a filetagem e o corte em postas. Os principais peixes filetados são o cação e a traíra.

Um dos peixes mais procurados é o peroá, devido a sua morfologia interna. Este peixe não possui "espinhos" intra musculares facilitando o seu consumo, sendo muito apreciado pela população local. Como a pesca (extrativista predatória) foi muito intensa em anos anteriores, este peixe esta sendo pouco encontrado na região.

De acordo com os comerciantes a traíra é o peixe mais vendido e também um dos mais procurados. A traíra, encontrada com freqüência em rios, represas e cursos (MELO FILHO, 2010), apesar de possuir muitos "espinhos", e não ser um peixe de grande valor comercial produz um filé considerado saboroso e muito apreciado em restaurantes da região. Em relação à ova, não comercializam separadamente, quando existe, estas são comercializadas juntamente com o peixe.

Os comerciantes mostraram preocupação com o volume de pescado comercializado, uma vez que, foi relatado que muitas pessoas deixam de ir ao Mercado Municipal da cidade por este não possuir uma infraestrutura adequada, principalmente relacionada a falta de estacionamento próprio o que dificulda a acessibilidade de grande parte da população.

\section{Conclusões}

A comercialização de espécies marinhas e de água doce no município de Campos dos Goytacazes - RJ esta se desenvolvendo lentamente, porém tem com grande potencial para o crescimento, principalmente devido aos recursos naturais da região e conscientização por parte dos pescadores e comerciantes em relação à época correta da pesca. Eles têm expectativas de melhoras desde que se tenha maior investimento em infraestrutura por parte do poder público. 


\section{Referências Bibliográficas}

BCB - Banco Central do Brasil. Relatório de inflação 2008, 2009 e 2010. Disponível em: www.bcb.gov.br. Acesso em: janeiro de 2011.

FIPERJ - A pesca no estado do Rio de Janeiro em 1997. Análise das estatísticas de desembarque. Disponível em:< http://www.fiperj.rj.gov.br> Acesso em: abril de 2011.

FIPERJ - Estatística pesqueira série 1990 a 2002. Disponível em:<http://www.fiperj.rj.gov.br> Acesso em: abril de 2011.

MELO FILHO, R. Traíra, o peixe mais genuinamente brasileiro. Disponível em:<http://www.destaquein> Sacrahome.net/node/314. Acesso em: julho de 2010.

MPA - Ministério da Pesca e Aguicultura - Produção pesqueira e aguícola - 2008 a 2009. Disponível em: http://www.mpq.gov.br> Acesso em março de 2011.

\section{Agradecimentos}

Aos pescadores e comerciantes do Mercado Municipal de Campos dos Goytacazes - RJ, pela cordialidade em nos receber e pela paciência ao responder às perguntas. 